Agro-Science Journal of Tropical Agriculture, Food, Environment and Extension Volume 13 Number 2 May 2014 pp. 50 - 58

ISSNIII9-7455

\title{
REACTIONS OF BAMBARA GROUNDNUT ACCESSIONS TO PHOTOPERIODS
}

\author{
Uchehara, C.P., Asiegbu, J. E. and Onyeonagu, C. C.* \\ Department of Crop Science University of Nigeria, Nsukka. \\ *Corresponding Author, e-mail: chike.onyeonagu@unn.edu.ng
}

\begin{abstract}
In two light-controlled experiments conducted at the Teaching and Research Farm of the Department of Crop Science, Faculty of Agriculture, University of Nigeria, Nsukka, the effects of six photoperiods $(8,10,12,14,16$ hours and natural photoperiod) on growth and flower induction in six accessions of bambara groundnut (TVsu 1023, TVsu 745, TVsu 323/764, TVsu 11, TVsu 9 and Yaudu (local) were studied at two different periods of the year. In experiment one, the design used was a $6 x 6$ factorial arrangement laid out in a completely randomized design (CRD) with 3 replications. The second experiment was a $5 \times 6$ factorial in CRD with three replications. In the first photoperiodic experiment (May 9, 1992 and August 10, 1992), Yaudu (local), TVsu 745, TVsu 11, TVsu 1023 and TVsu 9 showed a quantitative short day response to the number of leaves produced per plant, number of days to flower bud emergence and to anthesis. In the second growth chamber experiment (October 1992 to January 1993), TVsu 745, TVsu 764, TVsu 11, TVsu 1023 and Yaudu local exhibited a quantitative short day response in their number of days to flower bud emergence and to anthesis. As a result, they could be planted around July to take advantage of the short photoperiods of October to December for good crop.
\end{abstract}

Key words: photoperiodism, bambara groundnut, accessions, anthesis, number of flowers, leaf area

\section{INTRODUCTION}

Life processes of many plants have been shown to be influenced by the relative lengths of day and night (Linnemann, 1993; Craufurd et $a l .$, 2007). The distribution and time of maturity of different crops and crop varieties are influenced by photoperiodic responses, which when not well utilized in programming production (e.g. in the choice of planting date) may limit crop productivity.

$\mathrm{N}$-fixing legume crops may be a good component of a general plan to improve cropping system efficiency. For this purpose, crop suitability to specific environments must be established (Confalone et al., 2009).

In the recent past, much of the works done on photoperiodism of bambara groundnut (Vigna subterranean (L.) Verdc) were on the photo-inductive cycles. There has been no study on the effects of exposure of the crop to long day or short day conditions. There is need therefore, to investigate the photoperiodic responses of the
Nsukka popular

local accession alongside some other accessions as an aid for selecting varieties most suitable for the local conditions and conditions at different periods of the year. This will help to improve on the yield and reduce substantial loss of buds, flowers and immature pods due to unfavourable environments.

The objective of the investigation here reported was therefore to evaluate of the photoperiodic responses of six (6) bambara groundnut accessions as an aid to the choice of planting date for the different accessions under the local natural photoperiodic conditions.

\section{MATERIALS AND METHODS}

Two experiments were conducted at Nsukka May 9, 1992 and August 10, 1992, and between October 16, 1992 and January 31, 1993 to investigate the response of bambara groundnut to short and long photoperiods. Nsukka is located within latitude $06^{\circ} 52^{\prime} \mathrm{N}$ and 
longitude $07^{\circ} 24^{\prime} \mathrm{E}$ and at an altitude of 447 metres above sea level. The soil is an Ultisol of the Nkpologu series (Jungerius, 1964). The TVsu 1023, Tvsu 764, TVsu 745, TVsu 323, TVsu 11 and TVsu 9 accessions of bambara groundnut used for the experiment were obtained from the germplasm of the International Institute of Tropical Agriculture (IITA), Ibadan, Nigeria. These accessions were evaluated alongside a popular local accession commonly called "Yaudu".

\section{Soil-manure mixture preparation}

Topsoil from fallow land was collected, sieved and sterilized. Sterilization was done by heating the moist soil to $100^{\circ} \mathrm{C}$ for a period of 6 hours, the temperature being monitored by the use of a thermometer. The soil was then weighed and mixed with cured poultry manure and river sand in the ratio of 1 topsoil: 2 manure: 1 river sand by volume. The mixture was then bagged in black polyethylene bags with diameter $35 \mathrm{~cm}$. The quantity of soil-manure mixture in each bag was $10 \mathrm{~kg}$.

\section{Treatments, experimental design and layout}

The first experiment was a $6 \times 6$ factorial and was laid out in a completely randomized design with three replications. Treatment comprised six accessions of bambara groundnut and six photoperiods. The accessions were TVsu 1023, TVsu 745, TVu 323/764, TVsu 11, $\mathrm{TVu} 9$ and 'Yaudu' (local accession). The second experiment was a 5 x 6 factorial in CRD with three replications.

The photoperiods consisted of $8,10,12$, 14, 16 hours and naturally prevailing photoperiod. Each photoperiodic chamber measured $180 \mathrm{~cm}$ x $120 \mathrm{~cm}$ x $100 \mathrm{~cm}$. It was covered by a black cloth which was supported again by the use of polythene sheet. Five of the photoperiodis $(8,10,12,14$ and 16) were allocated completely at random. The natural photoperiod was not enclosed in a chamber to serve as a control. Other photoperiods were obtained by covering the chambers with black (opaque) material at the end of the corresponding photoperiod. For the 810 and 12 hour photoperiods, the chamber was covered daily at 1.0016 .0018 .00 respected and repeaed at 06.00 the following day. In the chamber receiving 14 hours and 16 hours of light, supplementary light was given, using fluorescent tube fittings (light intensity $=450$ flux) placed at bench level from 18.00 to 20.00 for the 14 - hour photoperiod, and from 18.00 to 22.00 for the The natural photoperiod which served as control was obtained from the number of hours for the period of civil twilight. The six bambara groundnut accessions were randomly placed in a block within each chamber, There were three replications.

Seeds for planting were soaked in water for 12 hours prior to planting. The seeds were planted in the polythene bags on the 9th of May, 1992, at the rate of three seeds per bag. These were later thinned down to one seedling per bag after germination. The seedlings were uniformly maintained before being placed into the appropriate photoperiodic chambers two weeks after planting. Data Collection Various agronomic measurements were taken included: number of leaves per plant starting from two weeks after planting. This was taken at twenty day intervals. The heights of the plants were measured by taking the distance from the ground to the shoot apex, using a metre rule. Other parameters measured were: number of days to first visible bud, number of days to anthesis, number of flowers per plant, leaf area at 50 days after planting (DAP) (done using automatic leaf area metre model MK2 GMT) and plant dry matter partitioning to the various fractions at 50 DAP. One plant each was cut at ground level from the pot and plants were separated into the different plant fractions of leaf, stem and root. These plant fractions were dried in the oven to a constant weight at $80^{\circ} \mathrm{C}$. The dried samples were weighed, using an electronic top loading balance.

\section{Concomitant observations}

Weather records for the periods of the experiment were collected from the Department of Crop Science Agro-meteorological Station. The records included air temperature, daylength and sunshine hours. The temperature of the photoperiodic chamber during the period of the experiment was also taken with a thermometer.

\section{RESULTS}

During the period of the growth chamber/photoperiodic experiments, daylength was comparatively highest from May to July and shortest in November, December and January (Table 1). Daylength never exceeded 12.3 hours. Chamber temperatures (maximum and minimum) were always considerably higher than natural air temperatures. Temperatures were relatively low in the months of July and August, intermediate in September, June and October and November and high in December, January and May. 


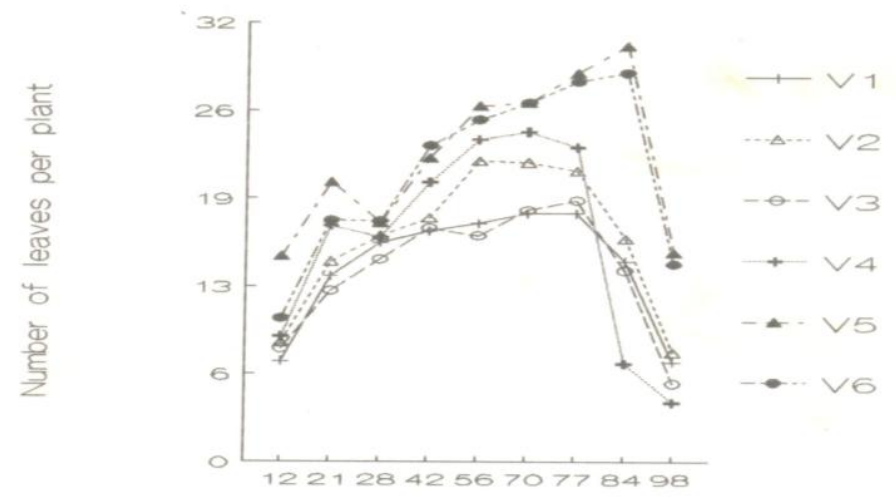

Days after planting

Fig. 1: Number of leaves produced by six bambara groundnut varieties at different stages of growth.

Variety $1=$ TVsu 1023 , Variety $2=$ TVsu 745 , Variety $3=$ TVsu 323 , Variety $4=$ Yaudu (local), Variety $5=$ TVsu 11 , Variety $6=$ TVsu 9

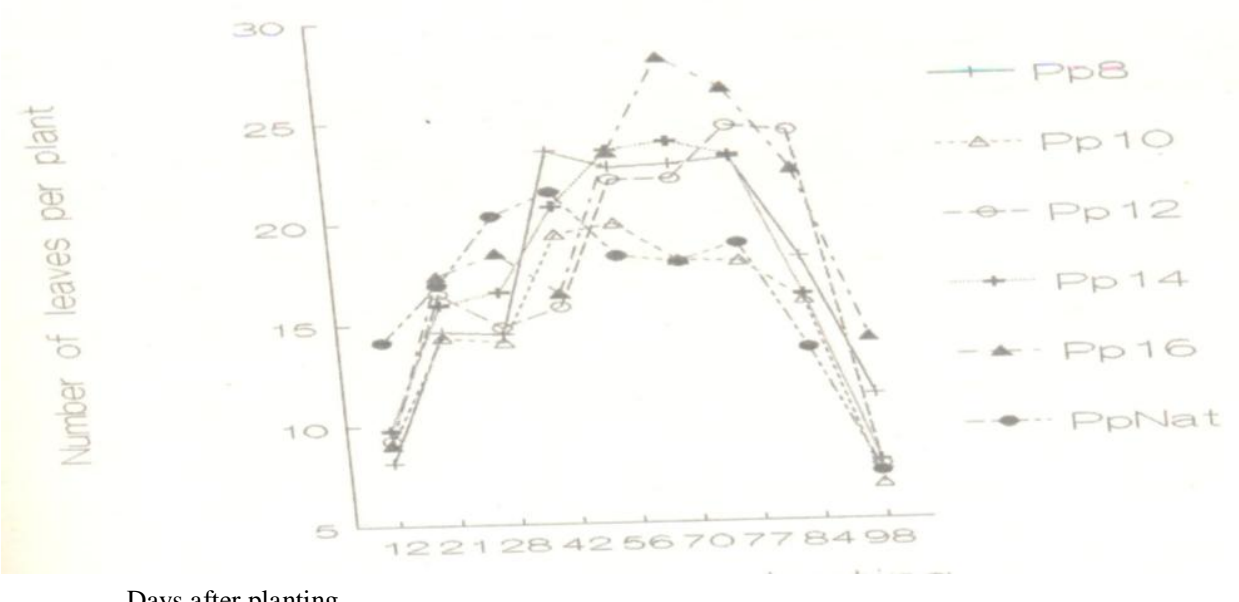

Fig.2. Effect of photoperiod on number of leaves produced by bambera groundnut at different stages of growth.

$\mathrm{Pp} 8=8$ hours photoperiod, $\mathrm{Pp10}=10$ hours photoperiod, $\mathrm{Pp} 12=12$ hours photoperiod, $\mathrm{Pp} 14=14$ hours photoperiod, $\mathrm{Pp} 16=16$ hours photoperiod, PpNat $=$ Natural condition.

N.B. $\mathrm{Pp}=$ Photoperiod; PpNat =. Natural condition.

Except for TVsu 11 and Yaudu (local), TVsu 9 produced significantly higher number of leaves than other accentor at 42 days after planting (Table 2). TVsu 1023 produced significantly the least although the value was not significantly less than those for TVsu 745 and TVsu 323. Number of leaves was highest with 8-hour photoperiod although the value was not significantly higher than the natural condition and 10 and 14- hour photoperiods. Photoperiod significantly influenced the number of leaves produced within each accession.
Consideration of leaf production at different stages of plant growth showed that accessions mostly followed the same trend in their responses except that 77 DAP 'Yaudu (local) exhibited a severe decline in number of leaves, giving the least number of leaves at 98 DAP (Fig. 1). TVgu 11 and TVsu 9 consistently had the highest number of leaves and sustained leaf production beyond 84 Others exhibited a decline in number of leaves 84 DAP TVu 1023 and TVsu 323 consistently had lower number of leaves. 
Table 1: Mean daylength and daily natural and experimental chamber temperatures from May 1992 to January 1993

\begin{tabular}{|c|c|c|c|c|c|c|c|c|c|}
\hline \multirow[b]{2}{*}{ Parameter } & \multicolumn{9}{|c|}{ Months of the year } \\
\hline & May & June & July & Aug. & Sept & Oct. & Nov. & Dec. & Jan. \\
\hline Daylenght (hours) & 12.3 & 12.3 & 12.3 & 12.2 & 12.1 & 12.0 & 11.5 & 11.5 & 11.5 \\
\hline Sunshine (hours) & 6.2 & 3.9 & 3.3 & 3.6 & 3.7 & 5.4 & 6.2 & 4.4 & 5.2 \\
\hline Chamber temp. $\left(\min .{ }^{0} \mathrm{C}\right)$ & 31.6 & 21.3 & 21.5 & 20.8 & 20.8 & 21.0 & 20.2 & 17.9 & 19.6 \\
\hline Chamber temp. $\left(\max .{ }^{0} \mathrm{C}\right)$ & 40.4 & 37.8 & 34.7 & 33.6 & 36.3 & 38.4 & 39.2 & 41.7 & 40.7 \\
\hline Air temp. $\left(\max .{ }^{0} \mathrm{C}\right)$ & 30.2 & 28.2 & 25.9 & 25.1 & 27.1 & 28.7 & 29.3 & 31.2 & 30.5 \\
\hline Air temp. (min. $\left.{ }^{0} \mathrm{C}\right)$ & 21.1 & 20.8 & 20.9 & 20.3 & 20.3 & 20.5 & 19.7 & 17.4 & 19.1 \\
\hline
\end{tabular}

Source: Department of Crop Science University of Nigerian Metrological Station

Table 2: Effects of photoperiod ${ }^{+}$and accession on the number of leaves per plant at 42 DAP*

\begin{tabular}{|c|c|c|c|c|c|c|c|}
\hline \multirow[b]{2}{*}{ Accession } & \multicolumn{7}{|c|}{ Photoperiod } \\
\hline & 8 & 10 & 12 & 14 & 16 & Natural condition 12.27 & Mean \\
\hline TVsu 1023 & 18.0 & 14.0 & 10.7 & 24.7 & 12.7 & 14.7 & 15.8 \\
\hline TVsu 745 & 21.0 & 19.3 & 12.0 & 14.0 & 15.3 & 21.0 & 17.1 \\
\hline TVsu 323 & 25.0 & 19.0 & 10.7 & 11.7 & 15.3 & 15.3 & 16.2 \\
\hline Yaudu (local) & 15.0 & 18.0 & 19.0 & 20.0 & 22.3 & 28.0 & 20.4 \\
\hline TVsu 11 & 30.7 & 25.3 & 14.0 & 23.0 & 16.0 & 24.0 & 22.2 \\
\hline TVsu 9 & 31.3 & 22.0 & 16.0 & 26.0 & 17.0 & 26.0 & 23.1 \\
\hline Mean & 23.5 & 19.6 & 13.7 & 19.9 & 16.4 & 21.5 & 19.1 \\
\hline $\begin{array}{l}\mathrm{LSD}_{0.05} \text { for } 2 \mathrm{a} \\
\mathrm{LSD}_{0.05} \text { for } 2 \mathrm{a} \\
{ }^{*} \mathrm{DAP}=\text { Days } \\
{ }^{+} \text {Chamber tem } \\
\text { Air temperatur }\end{array}$ & $\begin{array}{l}\text { ion or } \\
\text { ion or } \\
\text { plantin } \\
\text { ire:Mi } \\
\text { n. } 21.1\end{array}$ & $\begin{array}{l}\text { toperi } \\
\text { toperi } \\
49^{0} \mathrm{C} \text {; } \\
\text { Max. }\end{array}$ & $\begin{array}{l}\operatorname{Iax} .4 \\
.23^{0} \mathrm{C}\end{array}$ & & & & \\
\hline
\end{tabular}

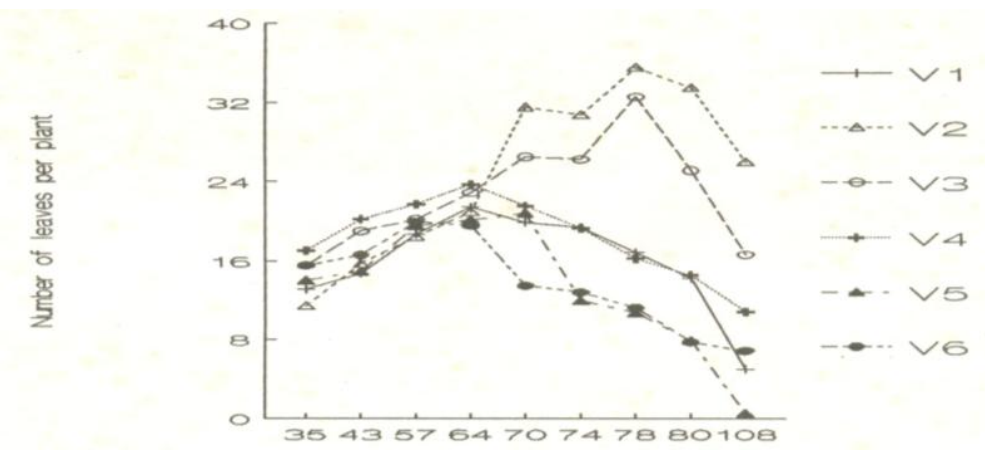

Days after planting

Fig.3 Number of leaves produced by six bambara groundnut varieties at different stages of growth.

$\mathrm{VI}=\mathrm{TVsu} 1023, \mathrm{~V} 2=\mathrm{TVsu} 745, \mathrm{~V} 3=\mathrm{TVsu} 764, \mathrm{~V} 4=$ Yaudu local, VS = TVsu 11, V6 = TVsu 9

Consideration of effects of photoperiod on leaf production at different ages of the plant showed that the peak of leaf production was 42 for 12-hour photoperiod (Fig. 2). Number of leaves declined drastically 77 or 84 DAP.

Flower bud emergence was significantly lowest under 10- hour photoperiod, followed by the natural condition (Table 3). On the average, Yaudu (local accession) was earliest to flower bud formation followed by TV5u 11 and TVsu 1023. Anthesis was earliest with 12-hour photoperiod followed by 10 -hour photoperiod. Effect of accession on days to anthesis followed the same pattern as for flower bud formation. Anthesis was earliest with 'Yaudu' and 12- hour photoperiod compared with other accessions at that or any other photoperiod. TVsu 11 was not particularly affected by long or short photoperiods with respect to bud formation and anthesis. Photoperiod as short as 8 hours delayed flower bud formation and anthesis. The local accession (Yaudu) and TVgu 11 were found to be mostly neutral in their responses to photoperiod although 8-hour photoperiod tended to delay bud formation and anthesis. TVsu 323 showed a more critical short day requirement of 10 to 12 hours. Although it produced bud that reached anthesis at natural daylength condition (12.26 hours), no anthesis occurred at $8,14,16$ or 16 -hour photoperiods. 
Table 3: Effects of photoperiod ${ }^{+}$and accession on number of days to flower bud emergence and anthesis

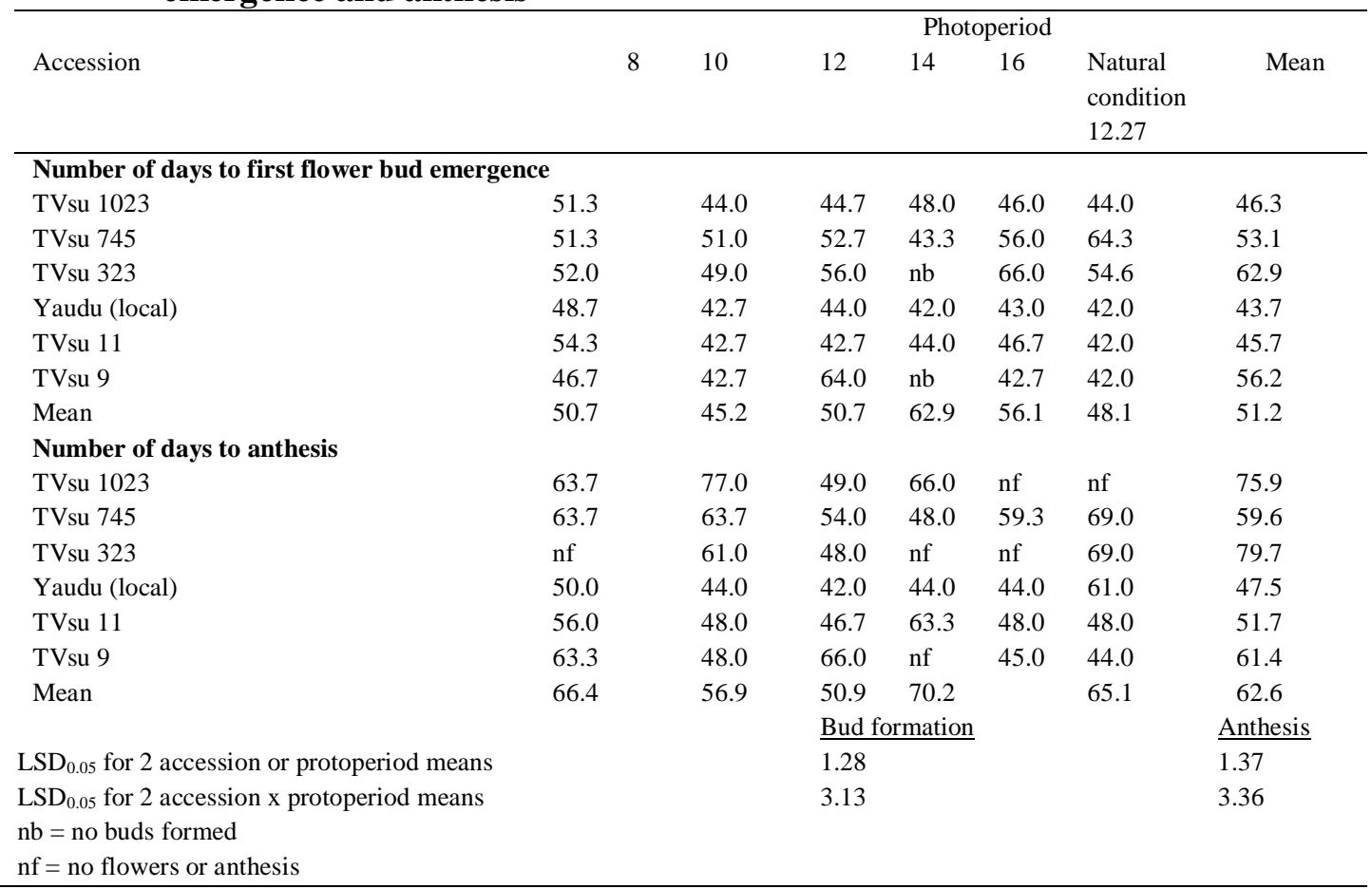

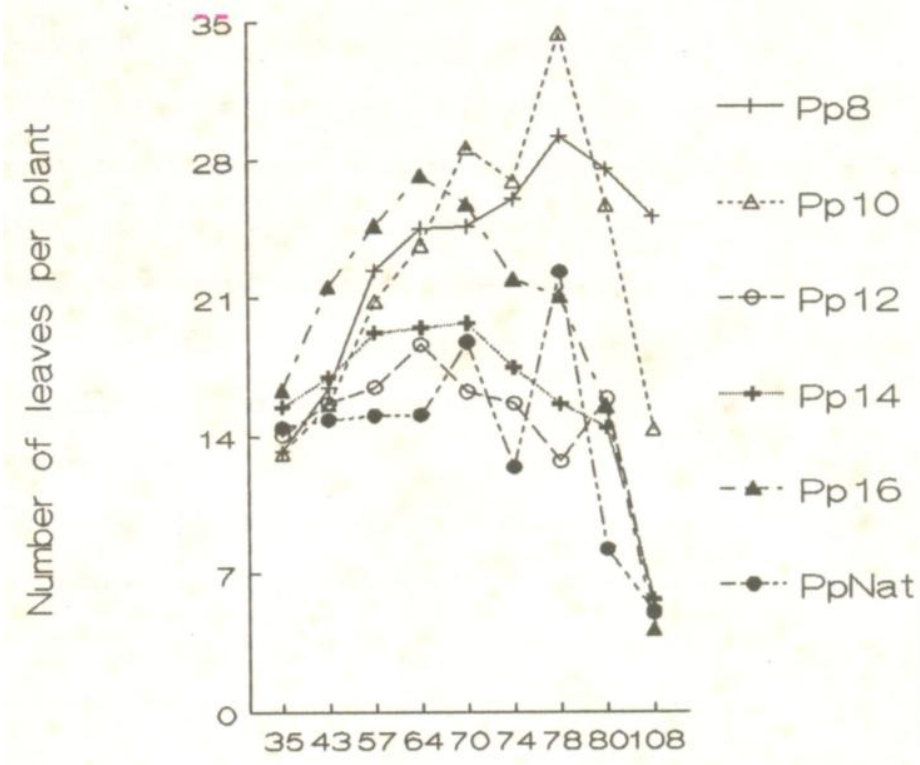

Days after planting

Fig.4. Effect of photoperiod on number of leaves produced by bambara groundnut at different stages of growth.

Pp8 $=8$ hours photoperiod, Pp10 = 10 hours photoperiod, Pp12 = 12 hours photoperiod, Pp14 14 hours photoperiod, Pp16 = 16 hours photoperiod, PpNat $=$ Natural conditions.

N.B. $\mathrm{Pp}=$ Photoperiod (hours) ; Nat $=$ Natural conditions 
Table 4: Effects of photoperiod ${ }^{+}$and accession on the number of leaves per plant at 50\ DAP*

\begin{tabular}{|c|c|c|c|c|c|c|c|}
\hline \multirow[b]{2}{*}{ Accession } & \multicolumn{7}{|c|}{ Photoperiod } \\
\hline & 8 & 10 & 12 & 14 & 16 & Natural condition 11.45 & Mean \\
\hline TVsu 745 & 12.7 & 14.0 & 21.0 & 57.0 & 21.0 & 22.0 & 24.6 \\
\hline TVsu 764 & 15.0 & 17.0 & 28.0 & 16.0 & 11.0 & 14.0 & 16.8 \\
\hline Yaudu (local) & 28.0 & 22.7 & 16.0 & 22.7 & 22.7 & 21.3 & 22.2 \\
\hline TVsu 11 & 24.0 & 13.7 & 14.0 & 39.0 & 11.0 & 0.0 & 16.9 \\
\hline TVsu 9 & 70.0 & 18.0 & 25.0 & 14.0 & 23.0 & 13.0 & 27.2 \\
\hline Mean & 30.0 & 17.1 & 20.8 & 29.7 & 17.7 & 14.1 & 18.0 \\
\hline \multicolumn{5}{|c|}{$\mathrm{LSD}_{0.05}$ for 2 protoperiod means } & \multicolumn{2}{|c|}{3.89} & \\
\hline \multicolumn{5}{|c|}{$\mathrm{LSD}_{0.05}$ for 2 accession means } & \multicolumn{2}{|c|}{3.55} & \\
\hline \multicolumn{5}{|c|}{$\mathrm{LSD}_{0.05}$ for 2 protoperiod $\times 2$ accession means } & \multicolumn{2}{|c|}{8.71} & \\
\hline
\end{tabular}

Chamber temperature: Min. $19.02^{\circ} \mathrm{C}$; Max. $40.41^{\circ} \mathrm{C}$

Table 5: Effects of photoperiod ${ }^{+}$and accession on leaf area $\left(\mathrm{cm}^{2}\right)$ per plant

\begin{tabular}{|c|c|c|c|c|c|c|c|}
\hline \multirow[b]{2}{*}{ Accession } & \multicolumn{7}{|c|}{ Photoperiod } \\
\hline & 8 & 10 & 12 & 14 & 16 & Natural condition 11.45 & Mean \\
\hline TVsu 745 & 65.0 & 97.3 & 117.0 & 479.0 & 145.7 & 310.0 & 202.3 \\
\hline Yaudu (local) & 193.0 & 111.0 & 144.0 & 116.7 & 118.0 & 115.3 & 133.0 \\
\hline TVsu 11 & 46.7 & 80.0 & 90.0 & 226.0 & 22.0 & 0.0 & 77.4 \\
\hline TVsu 9 & 294.0 & 62.0 & 196.7 & 46.0 & 103.0 & 74.0 & 129.3 \\
\hline \multicolumn{4}{|c|}{$\mathrm{LSD}_{0.05}$ for 2 protoperiod means } & \multicolumn{2}{|c|}{38.96} & & \\
\hline \multicolumn{4}{|c|}{$\mathrm{LSD}_{0.05}$ for 2 accession means } & \multicolumn{2}{|c|}{35.56} & & \\
\hline \multicolumn{4}{|c|}{$\mathrm{LSD}_{0.05}$ for 2 accession $\mathrm{x}$ protoperiod means } & \multicolumn{2}{|c|}{43.56} & & \\
\hline${ }^{+}$Air temperatu & Min. & $71^{0} \mathrm{C} ; \mathrm{N}$ & $29.27^{0} \mathrm{C}$ & & & & \\
\hline \multicolumn{4}{|c|}{ Chamber temperature: Min. $20.19^{\circ} \mathrm{C}$; Max. $39.15^{\circ} \mathrm{C}$} & & & & \\
\hline
\end{tabular}

Table 6: Effects of photoperiod ${ }^{+}$and accession on dry matter in plant parts at 50 DAP*

\begin{tabular}{|c|c|c|c|c|c|c|c|c|}
\hline \multirow{2}{*}{ Accession } & & \multicolumn{7}{|c|}{ Photoperiod (hours) } \\
\hline & & 8 & 10 & 12 & 14 & 16 & Natural condition 12.27 & Mean \\
\hline \multicolumn{9}{|c|}{ Leaf dry weight (g/plant) } \\
\hline \multicolumn{2}{|c|}{ TVsu 745} & 1.3 & 1.5 & 1.4 & 4.0 & 1.4 & 1.9 & 1.9 \\
\hline \multicolumn{2}{|l|}{ TVsu 764} & 0.6 & 1.0 & 1.5 & 0.5 & 0.3 & 1.0 & 0.8 \\
\hline \multicolumn{2}{|l|}{ Yaudu (local) } & 1.5 & 1.5 & 1.4 & 1.3 & 1.4 & 0.6 & 1.3 \\
\hline \multicolumn{2}{|l|}{ TVsu 11} & 0.7 & 0.5 & 2.1 & 1.3 & 0.8 & 1.1 & 1.1 \\
\hline \multicolumn{2}{|l|}{ TVsu 9} & 1.7 & 2.3 & 1.4 & 0.9 & 1.9 & 0.9 & 1.5 \\
\hline \multicolumn{2}{|l|}{ Mean } & 1.2 & 1.4 & 1.6 & 1.6 & 1.2 & 0.9 & 1.3 \\
\hline \multicolumn{9}{|c|}{ Stem dry weight (g/plant) } \\
\hline \multicolumn{2}{|l|}{ TVsu 745} & 0.2 & 0.2 & 0.2 & 0.2 & 0.4 & 0.3 & 0.3 \\
\hline \multicolumn{2}{|l|}{ TVsu 764} & 0.1 & 0.2 & 0.3 & 0.1 & 0.1 & 0.2 & 0.2 \\
\hline \multicolumn{2}{|l|}{ Yaudu (local) } & 0.2 & 0.4 & 0.2 & 0.4 & 0.3 & 0.1 & 0.3 \\
\hline \multicolumn{2}{|l|}{ TVsu 11} & 0.1 & 0.2 & 0.6 & 0.3 & 0.2 & 0.2 & 0.3 \\
\hline \multicolumn{2}{|l|}{ TVsu 9} & 0.2 & 0.3 & 0.3 & 0.1 & 0.5 & 0.2 & 0.3 \\
\hline \multicolumn{2}{|l|}{ Mean } & 0.2 & 0.3 & 0.3 & 0.2 & 0.3 & 0.2 & 0.3 \\
\hline \multicolumn{9}{|c|}{ Root dry weight (g/plant) } \\
\hline \multicolumn{9}{|c|}{ TVsu $745 \quad 0.12$} \\
\hline TVsu 764 & 0.06 & \multicolumn{2}{|l|}{0.15} & 0.12 & 0.10 & 0.07 & 0.13 & 0.11 \\
\hline Yaudu (local) & 0.08 & \multicolumn{2}{|l|}{0.06} & 0.04 & 0.32 & 0.11 & 0.07 & 0.11 \\
\hline TVsu 11 & 0.05 & \multicolumn{2}{|l|}{0.06} & 0.06 & 0.08 & 0.04 & 0.06 & 0.06 \\
\hline TVsu 9 & 0.11 & \multicolumn{2}{|l|}{0.07} & 0.07 & 0.07 & 0.07 & 0.09 & 0.08 \\
\hline Mean & 0.08 & \multicolumn{2}{|l|}{0.08} & 0.07 & 0.15 & 0.18 & 0.09 & 0.11 \\
\hline \multicolumn{9}{|l|}{ Total dry matter } \\
\hline TVsu 745 & 1.6 & \multicolumn{2}{|l|}{1.8} & 1.7 & 4.4 & 2.4 & 2.3 & 2.4 \\
\hline TVsu 764 & 0.8 & \multicolumn{2}{|l|}{1.4} & 1.9 & 0.7 & 0.5 & 1.3 & 1.8 \\
\hline Yaudu (local) & 1.8 & \multicolumn{2}{|l|}{2.0} & 1.6 & 2.0 & 1.8 & 0.8 & 1.7 \\
\hline TVsu 11 & 0.9 & \multicolumn{2}{|l|}{0.8} & 2.8 & 1.7 & 1.0 & 1.4 & 1.5 \\
\hline TVsu 9 & 2.0 & 2.7 & & 1.8 & 1.1 & 2.5 & 1.2 & 2.0 \\
\hline Mean & 1.4 & 1.7 & & 1.9 & 3.0 & 1.4 & 1.4 & 1.8 \\
\hline & & Leaf & Stem & $\underline{\text { Root }}$ & & & & \\
\hline $\mathrm{LSD}_{0.05}$ for $2 \mathrm{acc}$ & means & $\overline{0.22}$ & $\overline{0.04}$ & $\overline{0.08}$ & & & & \\
\hline $\begin{array}{l}\mathrm{LSD}_{0.05} \text { for } \\
\text { means }\end{array}$ & otoperiod & 0.25 & 0.05 & 0.08 & & & & \\
\hline $\begin{array}{l}\mathrm{LSD}_{0.05} \text { for } 2 \\
\text { protoperiod mea }\end{array}$ & ion $\times 2$ & 0.56 & 0.11 & 0.19 & & & & \\
\hline
\end{tabular}


Table 7: Effects of photoperiod ${ }^{+}$and bambara groundnut accession on the number of days to flower bud emergence and anthesis

\begin{tabular}{|c|c|c|c|c|c|c|c|}
\hline \multirow[b]{2}{*}{ Accession } & \multicolumn{7}{|c|}{ Photoperiod (hours) } \\
\hline & 8 & 10 & 12 & 14 & 16 & $\begin{array}{l}\text { Natural condition } \\
11.47\end{array}$ & Mean \\
\hline \multicolumn{8}{|l|}{ Number of days to first flower bud emergence } \\
\hline TVsu 1023 & 41.0 & 38.0 & 37.0 & 37.0 & 41.0 & 43.0 & 39.5 \\
\hline TVsu 745 & 41.0 & 53.3 & 37.0 & 43.0 & 44.7 & 43.0 & 43.7 \\
\hline TVsu 323 & 47.0 & 38.3 & 43.3 & 47.0 & 41.0 & 38.3 & 42.5 \\
\hline Yaudu (local) & 46.0 & 41.0 & 37.0 & 37.0 & 38.3 & 37.0 & 39.4 \\
\hline TVsu 11 & 38.3 & 43.0 & 52.0 & 52.0 & 65.3 & 52.0 & 50.4 \\
\hline Mean & 42.7 & 42.7 & 41.3 & 43.2 & 46.1 & 42.7 & 43.1 \\
\hline \multicolumn{8}{|l|}{ Number of days to anthesis } \\
\hline TVsu 1023 & 55.0 & $\mathrm{nf}$ & 47.7 & 42.0 & 44.0 & $\mathrm{Nf}$ & 47.2 \\
\hline TVsu 745 & 44.0 & 55.3 & $\mathrm{nf}$ & $\mathrm{nf}$ & 47.3 & 48.7 & 48.8 \\
\hline TVsu 323 & 50.7 & 45.7 & 53.3 & 58.0 & 42.0 & 44.0 & 48.9 \\
\hline Yaudu (local) & 54.3 & 46.0 & 40.0 & 40.0 & 40.0 & 40.0 & 43.5 \\
\hline TVsu 11 & 43.0 & 46.0 & $\mathrm{nf}$ & $\mathrm{nf}$ & 66.7 & 61.0 & 44.2 \\
\hline \multirow[t]{2}{*}{ Mean } & 49.4 & 48.3 & 47.0 & 46.7 & 48.0 & 48.4 & 46.5 \\
\hline & \multicolumn{2}{|c|}{ Bud formation } & \multicolumn{2}{|c|}{ Anthesis } & & & \\
\hline $\mathrm{LSD}_{0.05}$ for 2 accession or protoperiod means & \multicolumn{2}{|l|}{15.8} & \multicolumn{2}{|l|}{ N.A } & & & \\
\hline $\mathrm{LSD}_{0.05}$ for 2 accession $\mathrm{x}$ protoperiod means & \multicolumn{2}{|l|}{38.7} & \multicolumn{2}{|l|}{ N.A } & & & \\
\hline \multicolumn{8}{|l|}{ *Data for TVsu 9 not included in the analysis } \\
\hline N.A = Not analysed & & & & & & & \\
\hline
\end{tabular}

In the experiment conducted between October 16, 1992 and January 31, 1993, the natural condition with a photoperiod of 11.5 hours had the fewest number of leaves per plant followed by 10 and 16-hour photo periods (Table 4). Significantly higher numbers of leaves were produced with 8 and 14-hour photoperiodic treatments.

The TVsu 764 accession initially produced the least number of leaves but at 70 DAP, it clearly overtook others (Fig. 3). Yaudu (local) which always had the second highest number of leaves had similar number of leaves as TVSu 764 both of which reached their peak at 78 DAP after which the number of leaves sharply declined. All the other varieties reached the peak number of leaves at 64 DAP after which the decline was more gradual for each of the varieties.

Number of leaves was initially highest in 16 - hour photoperiod with the peak reached at 64 DAP and thereafter there was a progressire decline (Fig. 4). The 10-hour photoperiod attained the highest number of leaves compared with the other photoperiods as from 70 DAP, attained a peak at 78 DAP, with a sharp decline subsequently. The natural condition most of the time produced the lowest number of leaves. Remarkably, the 8-hour photoperiod maintained a sustained increase in number of leaves until the peak was attained at 78 DAP, after which the decline was slight such that a relatively high number of leaves was still maintained up to 108 DAP when the last record was made and when the others had lost most of their leaves.

Area per leaf was higher in 14-hour photoperiod compared with all others except the 12-hour photoperiod (Table 5). The least leaf area was obtained with 16 and 10-hour photoperiods. TVsu 745 had significantly highest leaf area per plant while TVsu 764 and TVg 11 had the least. With the 8-hour photoperiod, TVsu 9 had clearly a high leaf area compared with others and this high leaf area was not sustained in the other photoperiodic treatments.

Leaf dry weight was significantly lowest with the natural conditions in spite of its intermediate photoperiod (Table 6). This was followed by the 8-hour photoperiod while 12 and 14-hour photoperiods appeared to favour leaf dry matter accumulation. The stem dry matter was similarly lowest with the natural photoperiod and 8-hour photoperiod, while root dry matter accumulation appeared most favoured by 14 and 16-hour photoperiods. TVsu 745 and TVsu 11 had consistently less dry matter of leaves, stem and roots compared with the other accessions. Yaudu accumulated relatively higher dry matter in the leaf, stem or root in both the short and long photoperiods compared with the situation in the natural condition. This situation was also true with TVsu 9. 'Yaudu' local accession, TVcu 764, IVsu 75, TVsu 11 and TVsu 1023 exhibited a quantitative short day response to both the number of days to flower bud emergence and to anthesis (Table 7). 


\section{DISCUSSION}

Some earlier workers reported on photoperiodic cycles and their effects on flower induction (Bunt, 1973; Hunks and Rees, 1979). However, those studies reported were essentially on the effects of continuous short and long photoperiods on growth, development and flower induction in bambara groundnut although Linnemann (1993) studied the phenological development in bambara groundnut at constant exposure to photoperiods of 10 hours to 16 hours. Preliminary observations on photoperiodic regulation of phenologi development in bambara groundnut indicated marked differences in response to photoperiod among genotypes (Linnemann, 1991). Also (h) the present study, there were varietal differen in response to the effects of photoperiod on flower) induction and anthesis. Among accessions grown between May 1992 and August 1992, TVsu 745 and TVsu 1023 showed a quantitati(d) short day response to number days to flower bud emergence and to anthesis and as a result, should be planted between June and July for a good crop. TVU 323 showed a more critical short day requirement of 10 to 12.26 hours. Although it produced bud that reached anthesis at the natural day condition (12.26 hours), no anthesis occurred at 8, 14 and 16-hour photoperiods. Hence, TVsu 323 showed an obligate or a qualitative short day response to short days for the number of days to anthesis and as a result, would be planted in July for a good crop. TVsu 11 required a photoperiod of between 10 and 12.26 hours to produce flower buds early while photoperiod of 12 hours promoted number of days to anthesis and photoperiods of 8 and 14 hours delayed the number of days to anthesis. TVsu 9 required a photoperiod of 12.26 hours for early flower production.

The second experiment conducted between October 1992 and January 1993 showed interplay of photoperiod and higher temperatures during the period in enhancing vegetative growth, flower induction and anthesis. According to Vince-Prue and Cockshull (1981), Nishitani and Inouye (1981) and Confalone et al. (2009), vanatent in temperature and relative humidity regimes through the year could modify the photoperiodic responses of photoperiodicsensitive crop varieties. Yaudu local, TVsu 764, TVsu 745 exhibited a quantitative short day response to both the number of days to first bud emergence and anthesis and would be planted between June and July. Also, TVsu 11 showed a marked quantitative short day response to number of days to anthesis. TVsu 11 although exhibited a quantitative short day response to flowering, required shorter daylength of 8 to 10 hours to flower early and therefore should be planted at about July to grow well and take advantage of the short photoperiods of October to November. Although TVsu 1023 showed a quantitative short day's response to number of days to flower bud emergence and to anthesis, it required a marked daylenqth of 14 hours to flower early.

Similarly, in a work done on the photoperiod regulation of development in some bambara groundnut accessions by Linnemann (1991), four groups of accessions were distinguished on the basis of their responses to photoperiod, namely;

day neutral response to flowering with a quantitative response to short days for fruit set;

day neutral for flowering with an obligate response to short days for fruit set;

one with a quantitative response to short days for flowering with an obligate response to short days for fruit set; and

one with an obligate response to short days for flowering.

\section{SUMMARY AND CONCLUSION}

The bambara groundnut accessions differed markedly in responses to the effects of photoperiod especially with respect to the number of days to first flower bud emergence and to anthesis. Among the accessions grown between May, 1992 and August 1992, Yaudu (local) accession, TVsu 1023, TVsu 745, TVsu 11 and TVsu 9 showed a quantitative short day response to the number of leaves produced, number of days to flower bud emergence and to anthesis. As a result they could be planted around July to grow well and to take advantage of the short photoperiods of October to December. TVsu 323 produced buds at all photoperiods but could not attain anthesis at the short photoperiod of 8 hours or at any photoperiod above 12.26 hours, thereby exhibiting a qualitative short day response to the number of days to anthesis. Consequently, since TVsu 323 showed a more critical short day requirement of 10 to 12.26 hours, it would be best planted in July for a good crop.

The second experiment conducted between October, 1992 and January, 1993 showed interplay of photoperiod and higher temperature during the period in enhancing flower induction and anthesis. 'Yaudu' local accession, TVsu 764, TVsu 765, TVsu 11 exhibited a quantitative short day response to both the number of days to first flower bud emergence and to anthesis. TVsu 11 although exhibited a quantitative short day response to flowering, required shorter daylenqth of 8 to 10 hours to flower early. These accessions should, 
therefore, be planted between July and August. TVsu 1023 showed a quantitative short day response to the number of days to flower bud emergence and to anthesis although it required daylength of 14 hours to flower early.

\section{REFERENCES}

Bunt, A.C. (1973). Effect of season the carnation (Dianthus caryophyllus L.). II. Flower production. Journal of Horticultural Science 48: 315-325.

Hunks, G.R. and A.R. Rees (1979). Photoperiod and tulip growth. Journal of Horticultural Science 54(1): 39-46.

Confalone, A., Lizaso, J.I., Ruiz-Nogueria, B., Lopez-Cedron, F. and Sau, F. (2009). Growth, PAR use efficiency and components of field-grown Vicia faba L. under different temperature and photoperiod regimes. Field Crop Research.

http/www.elsevier.com/locate/fcr retrieved 26/05/13.

Craufurd, P.Q., Summerfield, R.J., Ellis, R.H. and Robert, E.H. (1997). Photoperiod, temperature and growth and development of cowpea. In: Singh, B.B., Moham, D.R., Raj, K.E.D. and Jackai (eds.). Advances in cowpea research. Copublication of International Institute of Tropical Agriculture (IITA) and Japan International Research Center for Agricultural Sciences (JIRCAS). IITA, Ibadan, Nigeria. Colorcraft, Hong Kong 375pp.
Jungerius, P.O. (1964). The soils of eastern Nigeria public service. Geologigue $d u$ Luxemboug XLVM: 185-198.

Linnemann, A.R. (1991). Preliminary observations on photoperiodic regulation of phenological development in bambara groundnut (Vigna subterranea). Field Crops Research 26: 295-304.

Linnemann, A.R. (1993). Phenological development in bambara groundnut (Vigna subterranea) at constant exposure to photoperiods 10-16 hours. Annals of Botany 71: 445-452.

Nishitani, T. and Inouye, J. (1981). The growth habits of bambara groundnut (Voandzeia subterranea) and Kersting's groundnut (Kertingiella geocarpa Harms.) effects of daylenqth and temperature on flowering. Japanese Journal of Tropical Agriculture 25(4): 163-169.

Vince-prue, D. and Cockshull, K.E. (1981). Photoperiodism and crop production. In: Physiological Processes Limiting Plant Productivity. Butterworths, London. 520pp. 